RESEARCH PAPER

\title{
Combining genetic gain and diversity under an individual selection method in a selected provenance of Eucalyptus cladocalyx
}

\author{
Freddy Mora ${ }^{1}$, and Javier Saavedra ${ }^{2}$ \\ ${ }^{1}$ Instituto de Biología Vegetal y Biotecnología, Universidad de Talca, 2 Norte 685, Talca, Chile. \\ ${ }^{2}$ Departamento de Biología, Facultad de Ciencias, Universidad de Chile. Las Palmeras 3425, Ñuñoa. \\ Santiago, Chile.
}

\begin{abstract}
F. Mora, and J. Saavedra. 2012. Combining genetic gain and diversity under an individual selection method in a selected provenance of Eucalyptus cladocalyx. Cien. Inv. Agr. 39(1): 177-184. Flowering traits are becoming important breeding objectives in Eucalyptus cladocalyx. Previous studies have confirmed that the trees from Cowell, Australia, respond well for early flowering under the arid conditions in the Southern Atacama Desert, Chile. This selected population was evaluated for flowering intensity at the end of the flowering season of 2009/2010 (February 2010). A Bayesian threshold tree model via Gibbs sampling was used in the data analyses. The model included the genotype-environment interaction (two sites) using a bi-character threshold model. The posterior mean of the genetic correlation between the sites was positive and high $(\mathrm{r}=0.8)$ and, according to the $95 \%$ credible interval $(0.44-0.96)$, it was significantly different from zero, indicating a non-significant interaction. The intensity of selection should be close to $11 \%$ to balance the gain and diversity after the individual tree selection in this breeding population.
\end{abstract}

Key words: Arid environmental conditions, Bayesian framework, breeding values, flowering components.

\section{Introduction}

Eucalyptus cladocalyx (F. Muell) is considered to be a high-value species for meliferous production under arid and semi-arid environmental conditions, and it is an economical alternative of proven profitability for the farmers of this sector (Montenegro et al., 2003). In arid environments, this species has shown adequate growth (Gleadow et al., 1998; Mora, 2006) and a relative resistance

Received September 28, 2010. Accepted July 6, 2011. Corresponding author: morapoblete@gmail.com to Phoracantha semipunctata, an insect introduced to Chile that affects Eucalyptus plantations (Hanks et al., 1994; Jorquera, 1998; Mora et al., 2007).

Early flowering and the flowering intensity have been considered as important selection components in E. cladocalyx, and, in previous studies, it was established that a Cowell provenance resulted in a higher flowering response under the arid conditions of the South Atacama Desert when compared to other Australian provenances (Mora et al., 2007).

From a statistical viewpoint, threshold models have been reported to be useful models for the 
genetic evaluation of categorical traits (Sorensen et al., 1994), enabling the estimation of genetic parameters, including heritability and genetic correlations (Roff, 2001). Within this context, for example, Stock et al. (2007) used a Bayesian threshold model, via the Gibbs algorithm, for the genetic evaluation of animals using phenotypic and genotypic information. The Gibbs algorithm belongs to the Markov chain - Monte Carlo (MCMC) methods and has been preferred over other MCMC methods because of the simplicity of its estimation (Sorensen and Gianola, 2002), which has allowed its incorporation into different statistics software, such as SAS (Statistic Analysis System; SAS-Institute, 1996), R (R Foundation for Statistical Computing, Vienna, Austria, 2010), WINBUGS (Bayesian inference Using Gibbs Sampling; Spiegelhalter et al., 2003) and MTGSAM (Multi-trait Gibbs Sampling for Animal Models; Van-Tassel and Van-Vleck, 1996).

Most genetic improvement programs are aimed at developing highly efficient genotypes, from a production point of view, and the combination of objectives based on genetic gains and diversity have been a focus of interest to breeders (Zheng et al., 1997). Among other factors, the genetic gain depends on selection intensity and heritability (a phenotypic variance ratio attributable to the genetic load of the individual) (Borrel, 2002). In addition, studies have shown the need to have a wide genetic basis (genetic diversity) for the long-term maintenance of the genetic gain in quantitative traits (Zheng, 1997; David et al., 2003; Kang et al., 2005).

The objectives of this study were as follows: to analyze the genetic gain and diversity under the individual selection method in one E. cladocalyx provenance preselected because of its flowering precocity, to evaluate E. cladocalyx trees genetically, according to their flowering abundance, under the Bayesian paradigm, and to estimate the genetic parameters of heritability and the genetic correlation between environments for this flowering component.

\section{Materials and methods}

A genetic evaluation of E. cladocalyx trees from the Australian provenance of the Eyre Peninsula (Cowell; 333' $\mathrm{S}, 136^{\circ} 40^{\prime} \mathrm{W}$; annual precipitation of $405 \mathrm{~mm}$ ) was performed.

We established two half-sib progeny trials in the Comunidad Agrícola Tunga Norte (313's, $71^{\circ} 19^{\prime} \mathrm{W}$; altitude of $297 \mathrm{~m}$; mean annual precipitation of $243.7 \mathrm{~mm}$; and mean annual temperature of $15^{\circ} \mathrm{C}$ ) and in Hacienda Agrícola Caracas ( $31^{\circ} 55^{\prime} \mathrm{S}, 71^{\circ} 27^{\prime} \mathrm{W}$; altitude of $167 \mathrm{~m}$; mean annual precipitation of $201.1 \mathrm{~mm}$; and mean annual temperature of $14.1^{\circ} \mathrm{C}$ ), both located in the Choapa Province. The trials consisted of twenty half-sib families arranged in a randomized block design (Mora et al., 2007).

The measurements of flowering abundance were performed according to an intensity scale measured at the end of the 2009/2010 flowering season (February of 2010). The scale included the following values (Cané-Retamales et al., 2011), according to the frequency of flowering events (whether capsules, flowers, or buds): 0 - absence of flowering events; 1 - few flowering events; 2 - presence of flowering events in $50 \%$ of the crown; and 3 - numerous flowering events through the crown.

The threshold model (Van-Tassel et al., 1998) refers to the following formulae:

$$
\begin{aligned}
& \eta=X \beta+Z a+\varepsilon \\
& \eta=\left[\begin{array}{ll}
\eta_{1} & \eta_{2}
\end{array}\right]^{T}=\left[\begin{array}{cc}
X_{1} & 0 \\
0 & X_{2}
\end{array}\right]\left[\begin{array}{l}
\beta_{1} \\
\beta_{2}
\end{array}\right]+\left[\begin{array}{cc}
Z_{1} & 0 \\
0 & Z_{2}
\end{array}\right]\left[\begin{array}{l}
a_{1} \\
a_{2}
\end{array}\right]+\left[\begin{array}{l}
\varepsilon_{1} \\
\varepsilon_{2}
\end{array}\right],
\end{aligned}
$$

where $\eta$ is the vector of a continuous random variable that is normally distributed, non-observable (unknown), and belonging to the flowering variable. The model corresponds to a bi-character model, where $\eta_{1}$ and $\eta_{2}$ are the observation vectors for the trait of interest, as measured in environments 1 and 2, respectively, which takes into account the genotype-environment interaction effect. $X$ is the 
incidence matrix for the $\beta$ vector, which represents a vector with the Block and Site effects. $Z$ is the incidence matrix of the additive effects vector of the individual plants, $a . \varepsilon$ is the residual vector. The variance components, heritability (sensu stricto) and the prediction of additive effects of the individual trees were investigated by Bayesian inference via the Gibbs algorithm.

The MTGSAM-Threshold package software (Van-Tassell and Van-Vleck, 1996) was used to obtain the posterior densities of the parameters of interest (Van-Tassel et al., 1998). The stationarity of the chains was evaluated by means of the Heidelberg and Welch (1983) method available in the statistics software, R-CODA (Cowles et al., 1995).

The heritability was estimated according to the following formula:

$\hat{h}^{2}=\frac{\hat{\sigma}_{a}^{2}}{\hat{\sigma}_{a}^{2}+\hat{\sigma}_{\varepsilon}^{2}}$,

where $\hat{\sigma}_{a}^{2}$ and $\hat{\sigma}_{\varepsilon}^{2}$ correspond to point estimates of the additive and residual variance, respectively, which were calculated from the posterior distributions.

The additive genetic association for a single trait measured in two environments was estimated with the following formula:

$\hat{r}=\frac{\hat{\sigma}_{a_{X Y}}}{\sqrt{\hat{\sigma}_{a_{X}}^{2} \cdot \hat{\sigma}_{a_{Y}}^{2}}}$,

where $\hat{\sigma}_{a_{X Y}}$ is the value of the posterior distribution of the additive covariance estimated between the environments. $\hat{\sigma}_{a_{X}}^{2}$ and $\hat{\sigma}_{a_{Y}}^{2}$ are the additive variances for each environment. An $r$ value close to 1 indicates a negligible genotype-environment interaction, whereas a low $r$ value (not significantly different from zero) indicates the significant presence of a genotype-environment interaction, and the ranking can be different in each site (Sykes et al., 2006; Mora et al., 2010).

The genetic gain was estimated using individual breeding values according to Mora et al. (2009), taking into account different selection intensities (varying from 0.8 to $40.8 \%$ ). In turn, the genetic diversity maintained after selection was estimated by means of the following formula proposed by Wei and Lindgren (1996):

$$
\hat{D}=\frac{\left[\left(\sum k_{f}\right)^{2} \sum k_{f}^{2}\right]}{\mathbf{N}_{p}},
$$

where $\hat{D}$ is the genetic diversity after selection, the expression of the numerator, $\left[\left(\sum_{k_{f}}\right)^{2} \sum k_{f}^{2}\right]$, corresponds to the effective number of selected progeny, $k_{f}$ is the number of selected individuals per family, and $\mathrm{N}_{p}$ corresponds to the original number of progeny.

\section{Results and discussion}

Before the configuration of the Gibbs chain, the Gauss-Seidel algorithm converged at iteration 84 , with a convergence criterion of $0.95 \mathrm{E}-9$. The Markov chains achieved convergence for all of the parameters using a burn-in of 50,000 iterations and a total of 250,000 Gibbs sampling rounds; 10,000 samples were retrieved to estimate the marginal posterior distributions. The results were recorded every 50 iterations to avoid auto-correlation. Table 1 shows the results from the individual threshold model using a Bayesian analysis via the Gibbs algorithm.

The mean heritability values were similar in both sites, as confirmed by the Bayesian credible intervals ( $95 \%$ of probability). The differences observed between the average and the modal value indicated the presence of asymmetry in the posterior distribution of the estimated parameters (Van Tassel et al., 1998). 
Table 1. Variance components and heritability, as estimated using a Bayesian approach (threshold tree model via Gibbs sampling), in Eucalyptus cladocalyx trees (from Cowell, Australia) evaluated in Northern Chile.

\begin{tabular}{lcccccc}
\hline & \multicolumn{3}{c}{ Point estimates } & & \multicolumn{2}{c}{ Interval estimates (95\%) } \\
\cline { 2 - 3 } \cline { 6 - 7 } Parameter & Mean & Median & Mode & & LC & UC \\
\hline Additive variance (Tunga) & 0.52 & 0.48 & 0.28 & & 0.14 & 0.97 \\
Additive variance (Los Vilos) & 0.38 & 0.36 & 0.25 & & 0.12 & 0.68 \\
Residual variance (Tunga) & 0.43 & 0.45 & 0.55 & & 0.09 & 0.76 \\
Residual variance (Los Vilos) & 0.31 & 0.31 & 0.38 & & 0.09 & 0.53 \\
Heritability (Tunga) & 0.53 & 0.52 & 0.33 & & 0.16 & 0.91 \\
Heritability (Los Vilos) & 0.54 & 0.54 & 0.40 & & 0.19 & 0.89 \\
\hline
\end{tabular}

LC, lower cut-off; UC, upper cut-off.

The high proportion of the phenotypic variations, attributable to the genotypic variation among the trees, is in agreement with the findings of Mora et al. (2007, 2009) and Cané-Retamales et al. (2011) for E. cladocalyx, Butcher et al. (2009) for Eucalyptus camaldulensis and Eucalyptus tereticornis, Wiltshire et al. (1998) for half-sib families of E. tenuiramis and Eucalyptus risdonii, and Chambers et al. (1996) for Eucalyptus globulus. However, in relation to the flower intensity or abundance, Butcher et al. (2009) found little flowering in the populations of E. camaldulensis in the arid regions of Australia, whereas Varghese et al. (2009) found inter-species differences in the fertile trees and fecundity percentages in the south of India.

Mora et al. (2007) found that the Cowell provenance exhibited an early flowering that was higher than other populations from Australia. The high heritability of the flowering intensity found in this population and the fact that this provenance is capable of flowering early are relevant aspects for the present small-scale breeding program. In addition, it is worth taking into account that both flowering abundance and precocity have been shown to be highly heritable traits. In fact, the heritability reported for early flowering in Cowell (Mora et al., 2007) confirmed a high value (posterior modal value corresponded to 0.53 ).

Table 2 shows the results of the bi-character threshold model analysis, which takes into ac- count the genotype-environment interaction effect. The genetic correlation was high (a mean of 0.8 and a mode of 0.9 ), indicating the absence of a genotype-site interaction. This result was confirmed by the credible interval, as this did not include the zero value ( $95 \%$ probability). Figure 1 shows the marginal posterior distribution of the genetic correlation in which the distribution asymmetry can be observed and a chart with the individual breeding values compared between the sites. The straight line shows an association measure between the breeding values (both sites), confirming the absence of a genotype-byenvironment interaction.

Table 2. Additive covariance and genetic correlation estimated for Eucalyptus cladocalyx trees (from Cowell, Australia) in Northern Chile using a Bayesian approach.

\begin{tabular}{lccccc}
\hline & & & \multicolumn{3}{c}{$\begin{array}{c}\text { Interval } \\
\text { estimates } \\
(95 \%)\end{array}$} \\
\cline { 2 - 6 } Parameter & Mean & Median & Mode & LC & UC \\
\hline $\begin{array}{l}\text { Additive } \\
\text { covariance }\end{array}$ & 0.36 & 0.34 & 0.20 & 0.08 & 0.70 \\
$\begin{array}{l}\text { Genetic } \\
\text { correlation }\end{array}$ & 0.80 & 0.86 & 0.91 & 0.44 & 0.96 \\
\hline
\end{tabular}

LC, Lower cut-off; UC, Upper cut-off.

Various studies have been conducted to measure the degree of the genotype-environment interaction in several species of the Eucalyptus genus (Costa et al., 2000; Lima et al., 2003; Silva et al., 2006). Indeed, the knowledge of the degree of interaction between the genotype and environment enables the evaluation of the stability of certain 

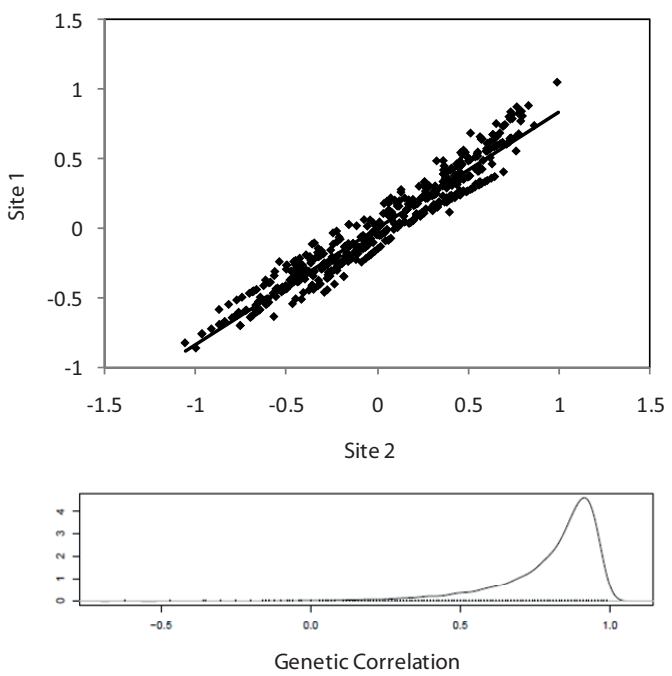

Figure 1. Estimates of breeding values for flowering in E. cladocalyx trees from Cowell (Australia). The breeding values were predicted using a Bayesian analysis (above). The marginal posterior distribution for the genetic correlation between two sites is shown below.

genotypes in a range of environments where their introduction is desired (Mora et al., 2007). The genotype-environment interaction in a population emerges when the genetic entities differ in their responses under different environmental conditions. The response patterns in different environments imply changes in the ranking of the genotypes and/or scale alterations (Silva et al., 2006).

Table 3 shows the predicted breeding values and the genetic diversity obtained after individual selection. The genetic gain (taking into account the selection intensities described in Table 2) varied from 22 to $55 \%$, whereas the genetic diversity varied from 19 to $74 \%$.

The genetic diversity is an important component within the context of the quality of a breeding program, and various studies have emphasized the relevance of keeping a reasonable diversity after selection (Furlani et al., 2005; Payn et al., 2008; Van Inghelandt et al., 2010). To obtain long-term genetic gains, the presence of genetic variability is required; therefore, it is important to examine both the population structure and the
Table 3. Genetic gain versus diversity, as estimated according to the selection intensity. The equilibrium point between both indexes was obtained to select approximately 66 trees (equivalent to $11 \%$ of selection intensity).

\begin{tabular}{cccc}
\hline $\begin{array}{c}\text { Selection } \\
\text { intensity } \\
(\%)\end{array}$ & $\begin{array}{c}\text { Selected } \\
\text { trees } \\
\text { (number) }\end{array}$ & $\begin{array}{c}\text { Genetic gain } \\
(\%)\end{array}$ & $\begin{array}{c}\text { Genetic } \\
\text { diversity } \\
(\%)\end{array}$ \\
\hline 0.8 & 5 & 55.0 & 19.2 \\
4.2 & 25 & 47.1 & 32.4 \\
7.5 & 45 & 43.0 & 37.7 \\
10.8 & 65 & 39.8 & 40.7 \\
14.2 & 85 & 36.8 & 42.5 \\
17.5 & 105 & 34.2 & 47.0 \\
20.8 & 125 & 32.0 & 54.5 \\
24.2 & 145 & 30.1 & 57.8 \\
27.5 & 165 & 28.3 & 63.6 \\
30.8 & 185 & 26.6 & 69.3 \\
34.2 & 205 & 25.0 & 71.6 \\
37.5 & 225 & 23.5 & 71.1 \\
40.8 & 245 & 22.1 & 74.1 \\
\hline
\end{tabular}

genetic diversity within certain genetic groups (Van Inghelandt et al., 2010). In the current study, when the predicted gain and diversity are considered equally relevant within the breeding program, the equilibrium point between the two would be a selection intensity of $11 \%$, a value that determines $40 \%$ of the genetic diversity maintained after selection, with a genetic gain of $40 \%$.

From the production point of view, the results of this study indicate high possibilities for the genetic improvement of E. cladocalyx, as based on the flower abundance for Northern Chile where plant materials that complement the existing native and endemic resource are required. Porter (1978) stated that the production of honey from Eucalyptus in arid areas depends on the number of hives in a given site, length of the harvesting period, rainfall, temperature before and during the harvest, and, most importantly, flowering abundance.

It can be concluded that the selection of trees based only on one site in particular would not affect the flowering intensity in another site because of the insignificant genotype-environment interaction. 
However, this conclusion may be considered valid only for this Australian provenance. It is possible to obtain a high genetic gain without neglecting the genetic gain that is maintained after the selection process and, thus, to improve the quality of the material in this small-scale breeding program.

\section{Acknowledgments}

The financial support for this work was provided by the Chilean National Science and Technology Research Fund (FONDECYT); project n`11090129. We thank the farmers of Tunga Norte and Hacienda Agrícola Caracas.

\section{Resumen}

F. Mora, y J. Saavedra. 2012. Ganancia y diversidad genética bajo el método selección individual en una procedencia seleccionada de Eucalyptus cladocalyx. Cien. Inv. Agr. 39(1): 177-184. Los componentes de florecimiento representan un importante criterio de selección en Eucalyptus cladocalyx. Estudios previos han confirmado que los árboles procedentes de Cowell, Australia, florecen precozmente bajo condiciones áridas del sur del Desierto de Atacama, Chile. Esta población seleccionada se evaluó en función de intensidad de florecimiento al final de la estación de florecimiento 2009/2010 (Febrero de 2010). Los datos se analizaron mediante un modelo umbral bayesiano vía algoritmo de Gibbs. El modelo incluyó la interacción genotipoambiente (en dos sitios) mediante un modelo umbral bi-caracter. La media a posteriori de la correlación genética entre sitios fue positiva y alta $(\mathrm{r}=0,8)$ y de acuerdo al del intervalo de credibilidad $(0,44-0,96), 95 \%$ de probabilidad, ésta fue significativamente distinta de cero, indicando una interacción no significativa. La intensidad de selección debiese ser cercana al $11 \%$ para balancear ganancia y diversidad genética, que se obtiene posterior a la selección de árboles individuales en esta población de mejoramiento.

Palabras clave: Componentes de florecimiento, condiciones ambientales áridas, enfoque Bayesiano, valores genéticos.

\section{References}

Borrel, Y. 2002. Loci microsatelite como marcadores genéticos para la mejora del rendimiento en acuicultura de especies marinas. Tesis de Doctorado. Departamento de Biología Funcional, Universidad de Oviedo. Oviedo, España. 147 pp.

Butcher, P.A., M.W. McDonald, and J.C. Bell. 2009. Congruence between environmental parameters, morphology and genetic structure in Australia's most widely distributed eucalypt, Eucalyptus camaldulensis. Tree Genetics \& Genomes 5:189-210.

Cané-Retamales, C., F. Mora, F. Vargas-Reeve, S. Perret, and R. Contreras-Soto. 2011. Bayesian threshold analysis of breeding values, genetic correlation and heritability of flowering intensity in Eucalyptus cladocalyx under arid conditions. Euphytica 178:177-183.

Chambers, P.G.S., N.M.G. Borralho, and B.M. Potts. 1996. Genetic analysis of survival in Eucalyptus globulus ssp. Globulus. Silvae Genetica 45:107-112.

Costa, R.B., M.D.V. Resende, A.J. Araujo, P.S. Gonçalves, and A.L.M. Martins. 2000. Genotypeenvironment interaction and the number of test sites for the genetic improvement of rubber trees (hevea) in São Paulo state, Brazil. Genet. Mol. Biol. 23:179-187. 
Cowles, M.K., N. Best, and K. Vines. 1995. Convergence diagnostics and output analysis. MRC Bioestatistics Unit, London, UK. 127 pp.

David, A., C. Pike, and R. Stine. 2003. Comparison of selection methods for optimizing genetic gain and gene diversity in a red pine (Pinus resinosa Ait.) seedling seed orchard. Theor. Appl. Genet. 107: 843-849.

Furlani, R.C.M., M.L.T. Moraes, M.D.V. Resende, E. Furlani-Junior, P.S. Goncalves, W.V. ValerioFilho, and J.R. Paiva. 2005. Estimation of variance components and prediction of breeding values in rubber tree breeding using the REML/ BLUP procedure. Genetics and Molecular Biology 28:271-276.

Gleadow, R.M., W.J. Foley, and I.E. Woodrow. 1998. Enhanced $\mathrm{CO} 2$ alters the relationship between photosynthesis and defence in cyanogenic Eucalyptus cladocalyx F. Muell. Plant, Cell and Environment 21:12-22.

Hanks, L.M., T.D. Paine, J.D. Millar, and J.L. Hom. 1994. Variation among Eucalyptus species in resistance to eucalyptus longhorned borer in Southern California. Entomologia Experimentalis et Applicata 74:185-194.

Heidelberger, P., and P.D. Welch. 1983. Simulation run length control in the presence of an initial transient. Operations Research 31:1109-1114.

Jorquera, P. 1998. Taladrador bajo la lupa. Revista Chile Forestal 23:26-27.

Kang, K.S, Y.A. El-Kassaby, S.U. Han, and C.S. Kim. 2005. Genetic gain and diversity under different thinning scenarios in a breeding seed orchard of Quercus accutissima. Forest Ecology and Management 212: 405-410.

Lima, J.T., M.C. Breese, and C.M. Cahalan. 2003. Genotype-environment interaction in wood basic density of Eucalyptus clones. Wood Science and Technology 34:197-206.

Montenegro, G., R. Pizarro, G. Avila, R. Castro, C. Ríos, O. Muñoz, F. Bas, and M. Gómez. 2003. Origen botánico y propiedades químicas de las mieles de la región mediterránea árida de Chile. Cien. Inv. Agr. 30:161-174.

Mora, F. 2006. Heredabilidad y valor genético (REML/BLUP) en genotipos de un eucalipto to- lerante a la sequía, en el norte de Chile. Ciencia Florestal 16:145-151.

Mora, F., S. Perret, C.A. Scapim, E.N. Martins, and M.P. Molina. 2007. Source-dependent blooming variability of Eucalyptus cladocalyx in the Region of Coquimbo, Chile. Cien. Inv. Agr. 34:99-106.

Mora, F., R. Gleadow, S. Perret, and C.A. Scapim. 2009. Genetic variation for early flowering, survival and growth in sugar gum (Eucalyptus cladocalyx F. Muell) in southern Atacama Desert. Euphytica 169:335-344.

Mora, F., S. Perret, C.A. Scapim, and E. Arnhold. 2010. Genetic parameters of growth and survival in Acacia saligna shrubs. Cien. Inv. Agr. 37:5-14.

Payn, H.G., W.S. Dvorak, B.J.H. Janse, and A.A. Myburg. 2008. Microsatellite diversity and genetic structure of the commercially important tropical tree species Eucalyptus urophylla, endemic to seven islands in eastern Indonesia. Tree Genetics \& Genomes 4:519-530.

Porter, J.W. 1978. Relationships between flowering and honey production of red ironbark, Eucalyptus sideroxylon (A. Cunn.) Benth., and climate in the Bendigo district of Victoria. Australian Journal of Agricultural Research 29:815-829.

Roff, D. 2001. The threshold model as a general purpose normalizing transformation. Heredity 86 : 404-411.

SAS-Institute. 1996. Statistical analysis system: user's guide. SAS Institute, Cary.

Silva, J.C., B.M. Potts, and G.W. Dutkowski. 2006. Genotype by environment interaction for growth of Eucalyptus globulus in Australia. Tree Genetics \& Genomes 2:61-75.

Sorensen, D., S. Andersen, D. Gianola, and I. Korsgaard. 1994. Bayesian inference in threshold models using Gibbs sampling. Genet. Set. Evol. 27: 229-249.

Sorensen, D., and D. Gianola. 2002. Likelihood, Bayesian, and MCMC Methods in Quantitative Genetics. Springer Springer-Verlag New York, USA. $740 \mathrm{pp}$.

Spiegelhalter, D., A. Thomas, N. Best, and D. Lunn. 2003. WinBUGS Version 1.4 Users Manual. MRC Biostatistics Unit, Cambridge. 
Stock, K., D. Ottmar, and I. Hoeschele. 2007. Bayesian estimation of genetic parameters for multivariate threshold and continuous phenotypes and molecular genetic data in simulated horse population using Gibbs sampling. BMC Genetics 8: 19.

Sykes, R., B. Li, F. Isik, J. Kadla, and H.M. Chang. 2006. Genetic variation and genotype by environment interactions of juvenile wood chemical properties in Pinus taeda L. Ann. For. Sci. 63:897-904.

Van Inghelandt, D., A.E. Melchinger, C. Lebreton, and B. Stich. 2010. Population structure and genetic diversity in a commercial maize breeding program assessed with SSR and SNP markers. Theor. Appl. Genet. 120:1289-1299.

Van Tassell, C.P., and L.D. Van Vleck. 1996. Multiple-trait Gibbs sampler for animal models: flexible programs for Bayesian and likelihood-based (co)variance component inference. Journal of Animal Science 74:2586-2597.

Van Tassell, C. P., L. D. Van Vleck, and K.E. Gregory. 1998. Bayesian analysis of twinning and ovu- lation rates using a multipletrait threshold model and Gibbs sampling. Journal of Animal Science 76:2048-2061.

Varghese, M., R. Kamalakannan, C.E. Harwood, D. Lindgren, and M.W. McDonald. 2009. Changes in growth performance and fecundity of Eucalyptus camaldulensis and E. tereticornis during domestication in southern India. Tree Genetics \& Genomes 5:629-640.

Wei, R.P., and D. Lindgren. 1996. Effective family number following selection with restrictions. Biometrics 52:198-208.

Wiltshire, R.J.E., J.B. Reid, and B.M. Potts. 1998. Genetic control of reproductive and vegetative phase change in the Eucalyptus risdonii-E. tenuiramis complex. Australian Journal of Botany 46:45-63.

Zheng, Y.Q., D. Lindgren, O. Rosvall, and J. Westin. 1997. Combining genetic gain and diversity by considering average coancestry in clonal selection of Norway spruce. Theor. Appl. Genet. 95: 1312-1319. 